\title{
Optimization of an RNA isolation procedure from plasma samples
}

\author{
PETRA CERKOVNIK ${ }^{1}$, ANDRAZ PERHAVEC ${ }^{2}$, JANEZ ZGAJNAR $^{2}$ and SRDJAN NOVAKOVIC $^{1}$ \\ Departments of ${ }^{1}$ Molecular Diagnostics, ${ }^{2}$ Surgical Oncology, Institute of Oncology Ljubljana, Ljubljana, Slovenia
}

Received April 4, 2007; Accepted May 11, 2007

\begin{abstract}
In this study, we aimed to optimize the isolation procedure of circulating RNA from large volumes of plasma. Simultaneously, the stability and integrity of RNA from plasma samples were examined. To investigate the isolation of circulating RNA, reverse transcription-PCR analysis in combination with capillary electrophoresis was used. The presence of amplifiable RNA in plasma from healthy volunteers and from breast cancer patients was analyzed. We found that circulating RNA in plasma was highly fragmented and degraded. Plasma RNA was most efficiently isolated from large volumes of samples after introducing the step of plasma concentration by evaporation and by using TRIzol LS reagent. A single freeze/thaw process had no significant effect on RNA integrity and quantity of plasma RNA. The average amount of RNA in plasma from breast cancer patients was lower than in plasma from healthy volunteers. The concentrating of large volumes of plasma facilitates isolation of plasma RNA and yields amplifiable RNA for at least fragments that are up to $310 \mathrm{bp}$ long.
\end{abstract}

\section{Introduction}

The discovery of circulating nucleic acids in the plasma and serum of cancer patients as well as healthy individuals has led to the potential use of circulating DNA and RNA for diagnostic purposes. More recently, the detection of circulating RNA has been reported as a potential approach for gene expression profiling in cancer patients. Circulating tumorderived RNA was first reported to be detectable in the plasma/ serum of cancer patients with nasopharyngeal carcinoma (1) and melanoma (2). Since then, a number of RNA targets have been detected in the plasma/serum of cancer patients, including the RNA species associated with the various telomerase components in patients with breast cancer $(3,4)$, colorectal cancer, follicular lymphoma (5) and hepatocellular carcinoma (6). Tyrosinase mRNA was reported to be detected

Correspondence to: Professor Srdjan Novakovic, Institute of Oncology Ljubljana, Zaloska 2, 1000 Ljubljana, Slovenia

E-mail: snovakovic@onko-i.si

Key words: plasma RNA, RNA isolation, RNA integrity in metastatic melanoma patients (7). Additionally, cytokeratin 19 and mammoglobin mRNAs were detected in the plasma of breast cancer patients, and were associated with poor prognosis (8). In the plasma of colorectal carcinoma patients, the recognition of $\beta$-catenin mRNA has recently been reported (9).

Considering the fact that plasma contains potent ribonucleases capable of destroying any free RNA, it was rather surprising that circulating RNA could be found preserved in the blood. In this regard, it has been proposed that circulating RNA in plasma is somehow protected from degradation by nucleases. Today, it is more or less accepted that RNA is protected by inclusion within apoptotic bodies (10-12).

According to the above reports, circulating RNA is a potentially promising substrate for the detection, tracking and prediction of cancer progression. However, there is still a huge limitation related to demanding and inconsistent extraction methods of low RNA amounts from plasma/serum. For this reason the extracted RNA is rather insufficient in quantity and quality for clinical applications (10). Therefore, the aim of this study was to improve the isolation of RNA from large volumes of plasma samples using TRIzol LS. A new step was introduced in the isolation procedure concentrating the plasma by evaporation prior to RNA isolation. The effectiveness of the new isolation protocol and its influence on RNA integrity was evaluated by direct determination of reverse transcriptase RT-PCR transcripts for porphobilinogen deaminase (PBGD) and glyceraldehyde 3-phosphate dehydrogenase (GAPDH). In addition, the effect of freezing and thawing of plasma samples on RNA quantity and integrity, as well as the differences between healthy volunteers and breast cancer patients, were evaluated. However, this article describes only the improvement of the RNA isolation procedure with no intention of evaluating its applicability in the case of cancer or other disease-related genes.

\section{Materials and methods}

Healthy volunteers and patients. Our study was approved by the Committee for Protocols and the Ethics Committee at the Institute of Oncology Ljubljana. Informed consent was obtained from all volunteers and patients included in the study.

Twenty-four healthy volunteers (14 females and 10 males), aged 24 to 57 years, and 28 female early breast cancer patients undergoing surgery (ranging in age from 34 
to 85 years) were included in the study. Pathological TNM classification of the tumors in our patients was as follows: 8 patients had stage I tumors $\left(\mathrm{pT}_{1 \mathrm{c}}, \mathrm{N}_{0}, \mathrm{M}_{0}\right), 8$ patients had stage IIA tumors $\left(\mathrm{pT}_{1 \mathrm{c}}, \mathrm{N}_{1 \mathrm{a}}, \mathrm{M}_{0}\right), 6$ patients had stage IIB tumors $\left(\mathrm{pT}_{2}, \mathrm{~N}_{1}, \mathrm{M}_{0}\right), 4$ patients with stage IIIA tumors ( $\mathrm{pT}_{2}, \mathrm{~N}_{2}, \mathrm{M}_{0}$; $\mathrm{pT}_{1 \mathrm{c}}, \mathrm{N}_{2}, \mathrm{M}_{0} ; \mathrm{pT}_{3}, \mathrm{~N}_{1}, \mathrm{M}_{0}$ ) and 2 patients had stage IIIC tumors $\left(\mathrm{pT}_{2}, \mathrm{~N}_{3}, \mathrm{M}_{0}\right)$. Blood samples from the breast cancer patients were collected on the day of surgery, and 1 and 10 days after.

Cell culture. Human breast adenocarcinoma cells MCF7 (American Type Culture Collection ATCC, Rockville, MD) were grown in Eagle's minimal essential medium (EMEM) supplemented with $10 \%$ fetal calf serum (FCS) (Sigma, St. Louis, MO), penicillin (100 units/ml; Pfizer, NY), streptomycin $(100 \mu \mathrm{g} / \mathrm{ml}$; Pfizer $)$ and gentamycin $(11 \mu \mathrm{g} / \mathrm{ml}$; Invenex, Chagrin Falls, $\mathrm{OH}$ ).

Isolation of mononuclear cells (MNC) from peripheral blood. Mononuclear cells (MNC) were isolated from $10 \mathrm{ml}$ of peripheral blood obtained from healthy volunteers using Fiqoll-Paque (Amersham Pharmacia Biotech AB, Uppsala, Sweden) according to the manufacturer's instructions.

Sample collection and processing of blood and plasma samples. Peripheral blood $(10 \mathrm{ml})$ was collected by venesection from each participant into EDTA-containing tubes (BD Vacutainer, Plymouth, UK). All blood samples were kept at $4^{\circ} \mathrm{C}$ and centrifuged within $2 \mathrm{~h}$ at $880 \mathrm{x}$ g for $10 \mathrm{~min}$ at $4^{\circ} \mathrm{C}$. Plasma was collected and again centrifuged at $880 \mathrm{x} \mathrm{g}$ for $10 \mathrm{~min}$ at $4^{\circ} \mathrm{C}$ to eliminate any remaining cells.

Plasma samples from healthy volunteers were aliquoted into three aliquots. RNA was isolated immediately from the first plasma aliquot. The second aliquot was stored at $-80^{\circ} \mathrm{C}$ until use. The third aliquot was concentrated and stored with TRIzol LS (Invitrogen, Life Technologies, Paisley, UK) at $-80^{\circ} \mathrm{C}$. Plasma from the breast cancer patients was stored at $-80^{\circ} \mathrm{C}$ until use.

\section{Optimization of RNA isolation from plasma}

Concentration of plasma samples by evaporation. Plasma samples were concentrated at $4^{\circ} \mathrm{C}$ in a concentrator (Eppendorf-Netheler-Hinz, Hamburg, Germany). One-half of each plasma sample $(2 \mathrm{ml})$ was separated into two aliquots and separately concentrated to $500 \mu 1$. The concentrated plasma was then mixed with TRIzol LS reagent. RNA was isolated from the other half of the plasma sample without applying the concentration step before isolation (unconcentrated plasma aliquot).

RNA isolation from plasma. Total RNA was isolated from $10^{6} \mathrm{MCF} 7$ cells, $10^{6} \mathrm{MNC}$, or from fresh and only oncefrozen/thawed plasma using TRIzol LS reagent (a monophasic solution of phenol and guanidine isothiocyanate). The plasma was mixed with TRIzol LS (1:3 ratio), and after 5 min of incubation at room temperature, chloroform was added to each sample, followed by $15 \mathrm{sec}$ of shaking and $10 \mathrm{~min}$ of incubation at $4^{\circ} \mathrm{C}$. The samples were then centrifuged at $12000 \mathrm{x} \mathrm{g}$ for $15 \mathrm{~min}$ at $4^{\circ} \mathrm{C}$. The upper aqueous phase was carefully transferred into a fresh tube and incubated for $16 \mathrm{~h}$ at $-20^{\circ} \mathrm{C}$ with isopropyl alcohol, $3 \mathrm{mM} \mathrm{Na}$-acetate, and with
RNase-free glycogen to allow the RNA precipitation. The mixture was then centrifuged at $12000 \mathrm{x}$ g for $30 \mathrm{~min}$ at $4^{\circ} \mathrm{C}$, and the supernatant was removed, while the pellet was washed by centrifugation $\left(7500 \mathrm{x} \mathrm{g}, 5 \mathrm{~min}, 4^{\circ} \mathrm{C}\right)$ with $75 \%$ ethanol. Finally, the supernatant was discarded, and the RNA pellet was dried for 5-10 min at room temperature, dissolved at $60^{\circ} \mathrm{C}$ for $10 \mathrm{~min}$ in $30 \mu \mathrm{l}$ of DEPC-treated water in the case of unconcentrated plasma or dissolved in $15 \mu 1$ of DEPCtreated water, joining the aliquots in a final volume of $30 \mu \mathrm{l}$ in the case of concentrated plasma and stored on ice.

Plasma samples stored with TRIzol LS. Concentrated samples frozen with TRIzol LS were quickly thawed and left at room temperature for $5 \mathrm{~min}$. The RNA was isolated as described above.

\section{RNA integrity}

Determination of integrity of isolated RNA by capillary electrophoresis. The RNA samples were analyzed for total RNA quality and level of degradation using an Agilent 2100 bioanalyzer and RNA 6000 Pico LabChip according to the manufacturer's instructions (RNA 6000 Pico assay kit, Agilent Technologies, Waldbronn, Germany). RNA integrity was determined using a micro-fluidic and fluorescence detection system, where sample components were electrophoretically separated and detected by their fluorescence after dye incorporation. Briefly, $1 \mu 1$ of each denatured RNA sample was added into the sample well loaded with gel-dye mix and buffer. The chip was vortexed for 1 min and run on the bioanalyzer. Total RNA sample integrity was determined against internal standards using the 2100 expert software tool (Agilent Technologies). Electropherograms showed the electrophoretic trace of the RNA sample, including the presence of $18 \mathrm{~S}$ and $28 \mathrm{~S}$ subunits and degradation products.

\section{Amplification}

RT-PCR amplification of PBGD and GAPDH. After RNA isolation, reverse transcription (RT) of RNA to cDNA was performed using a GeneAmp RNA PCR Core kit (Applied Biosystems, Roche Molecular Systems, Branchburg, NJ, USA) according to the manufacturer's instructions with a slight modification for plasma samples (3). PCR amplification was performed in a thermocycler (Perking-Elmer, Applied Biosystems). The presence of amplifiable cell-free circulating RNA in the tested plasma sample was verified using two housekeeping genes; glyceraldehyde 3-phosphate dehydrogenase (GAPDH) (NCBI, accession no. XR_018317) and porphobilinogen deaminase (PBGD) (NCBI, accession no. NM_000190). The amplification primers were synthesized by TIB MolBiol (Berlin, Germany). GAPDH-forward, 5'CGG AGT CAA CGG ATT TGG TCG TAT-3'; GAPDHreverse, 5'-AGC CTT CTA CAT GGT GGT GAA GAC-3'; PBGD-forward, 5'-TGT CTG GTA ACG GCA ATG CGG CTG CAA C-3'; and PBGD-reverse, 5'-TCA ATG TTG CCA CCA CAC TGT CCG TCT-3'. PCR amplification was performed in the same reaction tube as the RT by adding new reagents and adjusting the final concentration for all reagents in the reaction mixture. The final mixture volume for the GAPDH or PBGD PCR was thus increased to $100 \mu 1$. In the case of GAPDH the mixture consisted of $1 \mathrm{X}$ PCR buffer II, 
2.5 U AmpliTaq DNA polymerase (Applied Biosystems), $1.7 \mathrm{mM} \mathrm{MgCl}_{2}$ and $0.075 \mu \mathrm{M}$ of GAPDH primers. For PBGD amplification, the final mixture consisted of 1X PCR Gold buffer, 2.5 U Gold polymerase (Applied Biosystems), $2 \mathrm{mM}$ of $\mathrm{MgCl}_{2}$ and $0.1 \mu \mathrm{M}$ of PBGD primers. The PCR conditions were as follows: initial incubation at $94^{\circ} \mathrm{C}$ for 2 min for GAPDH $\left(94^{\circ} \mathrm{C}\right.$ for $12 \mathrm{~min}$ in the case of PBGD), followed by 50 cycles of amplification: $94^{\circ} \mathrm{C}$ for $30 \mathrm{sec}, 65^{\circ} \mathrm{C}$ for $1 \mathrm{~min}$, $72^{\circ} \mathrm{C}$ for $1 \mathrm{~min}$ for $\mathrm{GAPDH}$; and $94^{\circ} \mathrm{C}$ for $50 \mathrm{sec}, 59^{\circ} \mathrm{C}$ for $1 \mathrm{~min}, 72^{\circ} \mathrm{C}$ for $1 \mathrm{~min}$ in the case of PBGD, and final elongation at $72^{\circ} \mathrm{C}$ for $10 \mathrm{~min}$.

PCR product analysis. The PCR products were analyzed by capillary electrophoresis using the bioanalyzer and a DNA 1000 assay kit (Agilent Technologies), according to the manufacturer's instructions. This method allowed the determination of size (in $\mathrm{bp}$ ) and concentration ( $\mathrm{ng} / \mu \mathrm{l})$ of the PCR products. Briefly, $1 \mu 1$ of sample was added into the sample well loaded with gel-dye mix and buffer. The chip was vortexed for $1 \mathrm{~min}$ and placed in the bioanalyzer. After chip run, the samples (PCR products) moved through the micro-channels and were electrophoretically separated. The fluorescence of the PCR products was detected and translated into electropherograms. Quantification of PCR products was automatically determined against internal standards using the 2100 expert software tool.

Sequencing of PCR products. The amplified PBGD products were sequenced by Sequieserve GmbH (Vaterstetten, Germany), while the amplified GAPDH products were sequenced in our laboratory using the ABI PRISM ${ }^{\circledR} 310$ Genetic analyzer (Applied Biosystems, London, UK). The data were collected with ABI PRISM 310 software (Applied Biosystems), and the results were analyzed with the ABI PRISM DNA sequencing analysis software (Applied Biosystems). Sequence data were analyzed utilizing the Gene Runner software tool, version 3.05.

Statistical analysis. Statistical analysis was performed using SigmaStat SPSS, version 3.0. Results were presented as the means and corresponding standard deviations (SD). The statistical significance of the difference between the differently treated aliquots of plasma from healthy volunteers was evaluated using one-way ANOVA. The student's twotailed t-test was used for the evaluation of the statistical significance of the difference between groups of healthy volunteers and breast cancer patients. $\mathrm{P}<0.05$ was considered as statistically significant.

\section{Results}

In practice, the isolation of RNA from a large volume of plasma involves certain critical steps: general handling of the plasma samples, precipitation of low concentrations of RNA from excessively large aqueous phase volumes, as well as collection of slight RNA pellet. To improve the plasma RNA isolation procedure in the classical protocol for RNA isolation using TRIzol LS, a step to reduce the initial plasma sample volume was introduced. To investigate the influence of some of the critical steps during isolation, RNA integrity and
A.

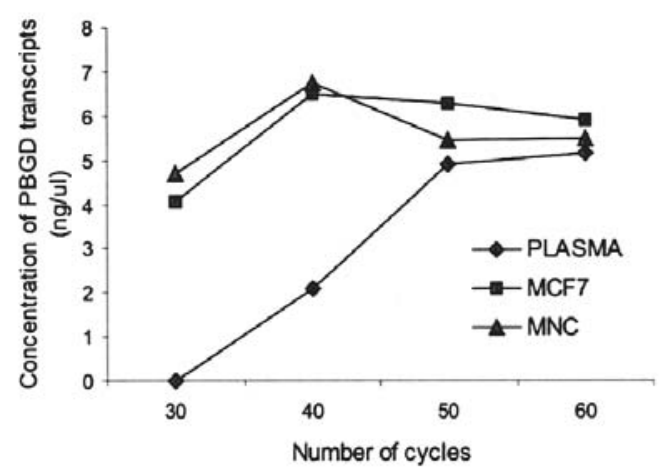

B.

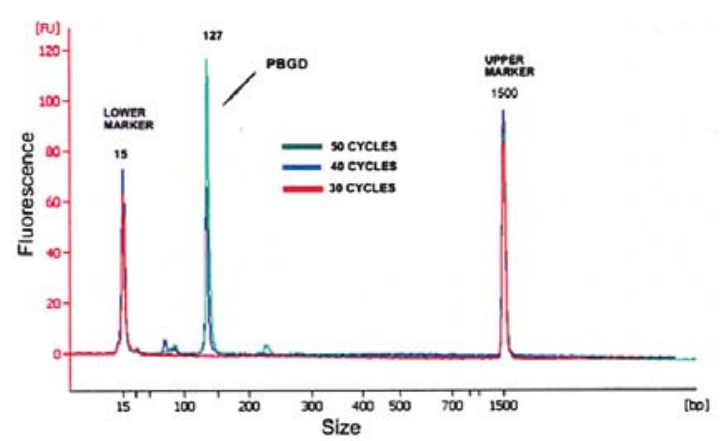

Figure 1. Quantification of PCR products after different numbers of cycles. (A) Comparison of the concentrations of PBGD transcripts after 30, 40, 50 and 60 PCR cycles of cDNA obtained with reverse transcription of RNA from plasma samples, MCF7 cells or MNC. The RNA isolated from cells was amplified exponentially to 35-40 cycles. RNA isolated from plasma samples was exponentially amplified to 45-50 cycles. (B) Electropherogram of PBGD transcripts after 30,40 and 50 cycles of RT-PCR amplification of RNA isolated from plasma.

quantity was checked after concentrating the plasma samples, and after the freezing and thawing of plasma samples prior to RNA isolation.

Effect of freezing and thawing on plasma RNA. To determine whether the freezing of plasma samples affects RNA concentration, we analyzed aliquots of fresh and once-frozen plasma samples from healthy volunteers. RNA concentrations were determined by quantifying the amounts of PBGD transcripts after reverse transcription and PCR amplification of the isolated RNA. Quantification was performed using a semi-quantitative method on the Agilent 2100 bioanalyzer. This capillary electrophoresis procedure allowed high resolution $( \pm 5.00 \%)$, sizing $( \pm 10.00 \%)$ and quantification $( \pm 30.00 \%)$ accuracy. It was determined experimentally that the amount of isolated RNA critically influenced the PCR reaction. The RNA isolated from cells was amplified exponentially to 35-40 cycles. However, when the plasma RNA was amplified, the exponential PCR amplification phase was prolonged to 45-50 cycles. Therefore, the quantified PCR products of the plasma samples still reflected the starting cDNA quantities (Fig. 1). Among samples collected from 24 healthy volunteers, 23 (95.80\%) had 
detectable levels of PBGD in fresh and once-frozen plasma, either with or without TRIzol LS. In 1 of 24 plasma samples $(4.20 \%)$, we failed to detect the presence of PBGD transcripts in all 3 aliquots of differently pre-treated plasma. In Fig. 2, one of the 23 successfully amplified RNA plasma samples is presented. The PBGD fragment (127 bp long) was amplified in all 3 aliquots of plasma sample. No significant difference was found for average concentrations of PBGD transcripts among fresh and once-frozen plasma, with or without TRIzol LS ( $\mathrm{P}=0.51)$.

Concentration of plasma samples by evaporation. Concerning the unsuitability of isolation of small amounts of RNA from a large volume of plasma, we concentrated one-half of the initial plasma samples in the concentrator. The empirically determined minimal volume of concentrated samples using the evaporation method was $500 \mu \mathrm{l}$. The additional evaporation of samples resulted in too high a protein content, which prevented efficient RNA isolation. The isolated RNA from concentrated aliquots was compared for quantity and quality with the RNA isolated from unconcentrated aliquots from the same plasma samples obtained from healthy volunteers. Quality and quantity were assessed by determination of PBGD and GAPDH transcripts after RT-PCR. Our results showed that the concentrating procedure performed on the plasma samples did not affect RNA integrity, since the characteristic products were observed in both concentrated and unconcentrated aliquots of the samples (Fig. 3). There was no significant difference in the amount of PBGD and GAPDH transcripts between the concentrated and unconcentrated aliquots of the same plasma sample $(\mathrm{P}=0.32)$. The amplified PBGD and GAPDH products were confirmed by sequencing.

Integrity of plasma RNA in healthy volunteers. We determined plasma RNA integrity in 24 samples from healthy volunteers using the capillary electrophoresis described in Materials and methods. As expected, the RNA in the plasma was highly fragmented and degraded in comparison with the RNA extracted from MNC (Fig. 4). Despite the high fragmentation (degradation) of plasma RNA, the isolated RNA was still transcribed and amplified for PBGD in $95.80 \%$ of the plasma samples (Fig. 5A-C). In $4.20 \%$ of the plasma samples, the extracted RNA was too degraded for efficient reverse transcription to cDNA and amplification of PBGD (Fig. 5D). There was no significant difference in RNA integrity after the freezing of plasma samples (Fig. 5A-C).

Isolation of plasma RNA from breast cancer patients. To determine whether there was any difference in the quality and quantity of plasma RNA in breast cancer patients, we compared the results of RT-PCR for PBGD amplification in these patients with the results obtained from healthy volunteers. Since there was no significant difference in the number of successfully RNA-isolated samples from healthy females and healthy males (as well as in their PBGD concentrations), females and males were included in the control group $(\mathrm{P}=0.73)$. Only once-frozen plasma samples were used in this part of the study. PBGD was amplified in 54 of 67 tested samples from breast cancer patients $(80.60 \%)$. As previously indicated, PBGD was detected in 23 of 24 plasma samples

\section{A1. FRESH PLASMA}

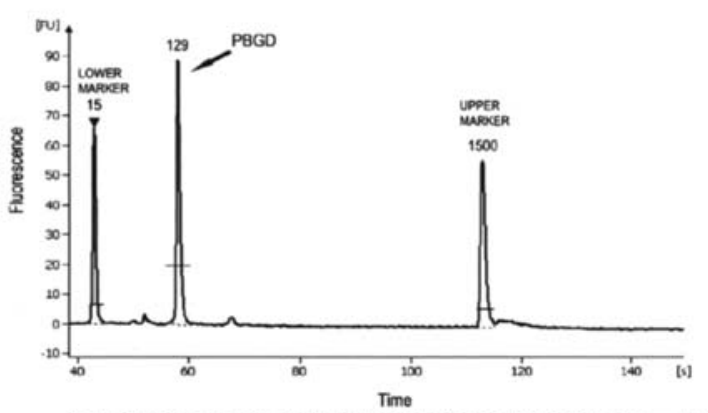

A2. ONCE-FROZEN PLASMA WITHOUT TRIZOILS

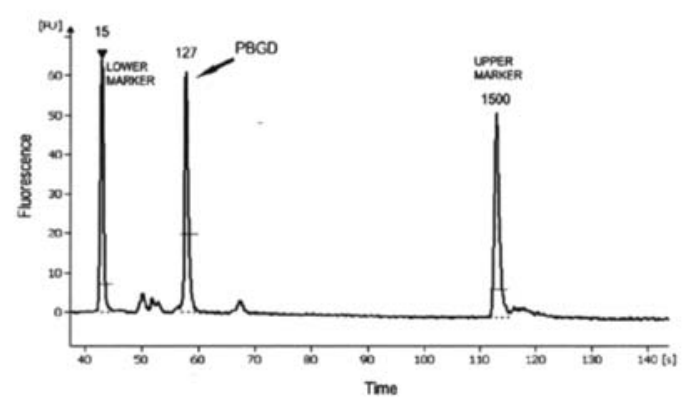

A3. ONCE-FROZEN PLASMA WITH TRIZOI LS

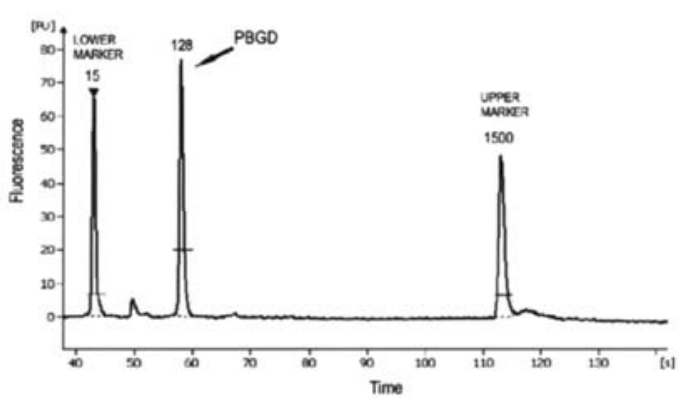

B.

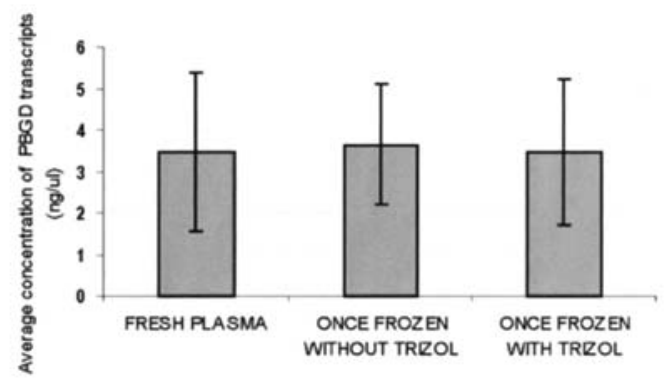

Figure 2. Determination of the quality and quantity of RNA isolated from the plasma samples of 24 healthy volunteers. (A) Electropherograms of PBGD transcripts after RT-PCR amplification of RNA isolated from fresh plasma and once-frozen plasma samples with or without TRIzol LS. (B) Average amounts of PBGD transcripts (mean \pm SD) determined in fresh and once-frozen plasma samples, with or without TRIzol LS.

from healthy volunteers $(95.80 \%)$. There was a significant difference in average RNA concentration between breast cancer patients and healthy volunteers (mean $1.87 \mathrm{ng} / \mu 1$, 95.00\% CI 1.15-2.59, DF=92 and $\mathrm{P}<0.001)$. Cancer patients had a lower average RNA concentration $(1.78 \pm 1.48 \mathrm{ng} / \mu \mathrm{l})$ compared to healthy volunteers $(3.65 \pm 1.45 \mathrm{ng} / \mu \mathrm{l})$ (Fig. 6). As in plasma from healthy volunteers, the RNA in plasma from breast cancer patients was also highly degraded (Fig. 4). 


\section{A. UN-CONCENTRATED ALIQUOT}

PBGD

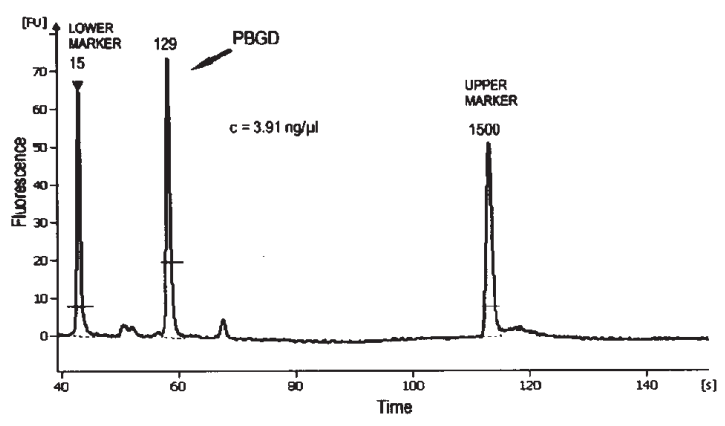

B. CONCENTRATED ALIQUOT

PBGD

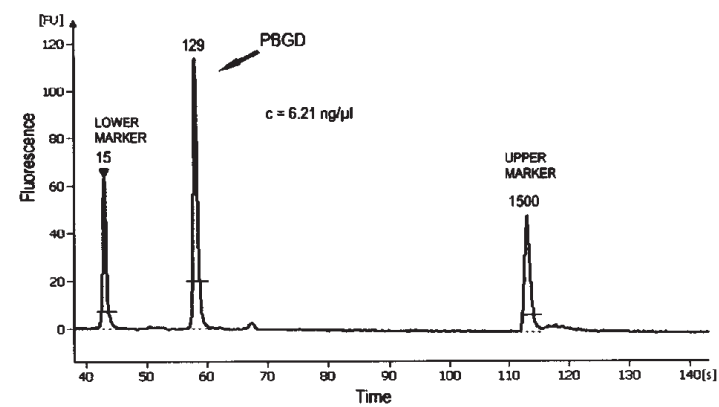

GAPDH

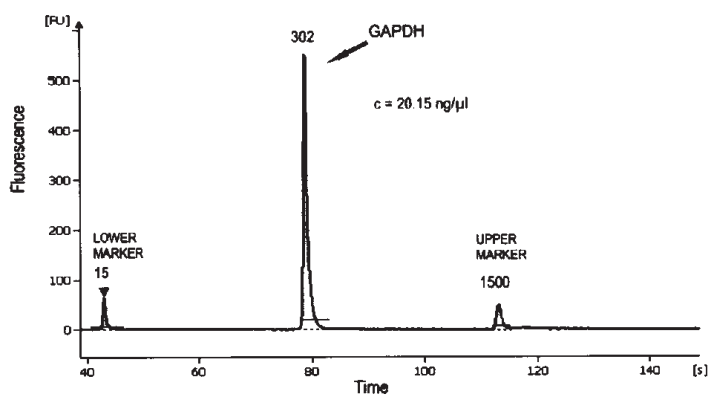

GAPDH

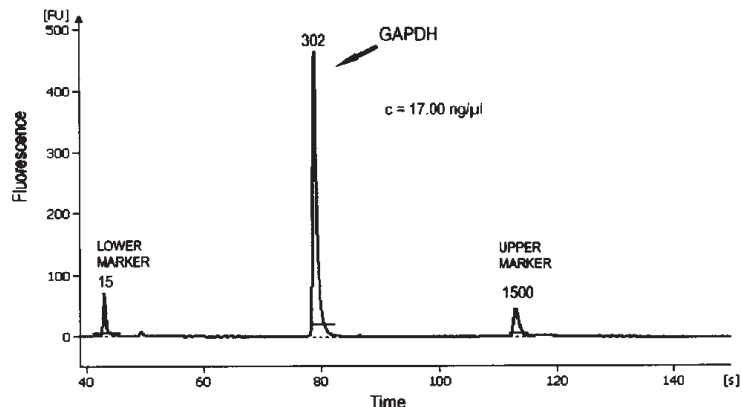

Figure 3. Effect of plasma concentrating on PBGD and GAPDH RT-PCR amplification. PBGD (127 bp) and GAPDH (309 bp) transcripts after RT-PCR amplification of RNA isolated from unconcentrated (A) and concentrated (B) aliquots of the same plasma sample. The concentrating of plasma samples was found to have no significant effect on RNA integrity.

HEALTHY VOLUNTEER

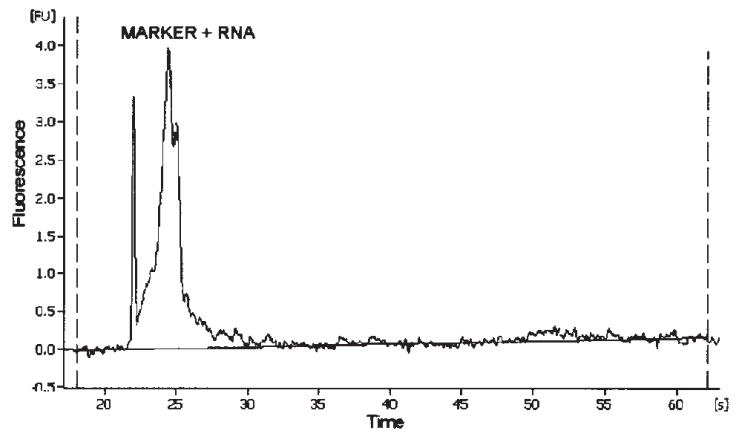

BREAST CANCER PATIENT

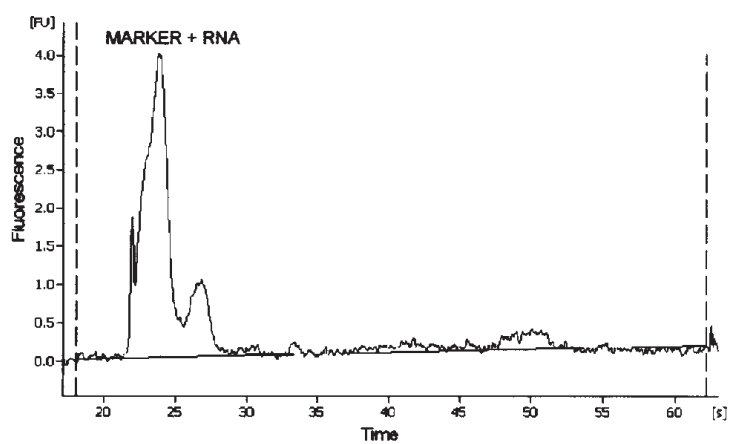

MNC

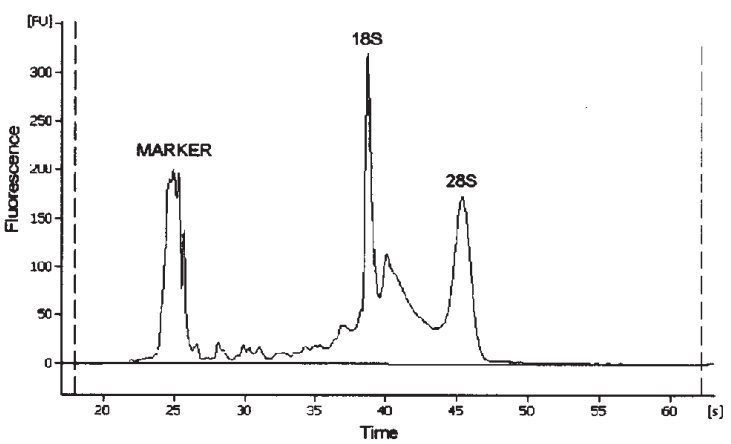

MCF7

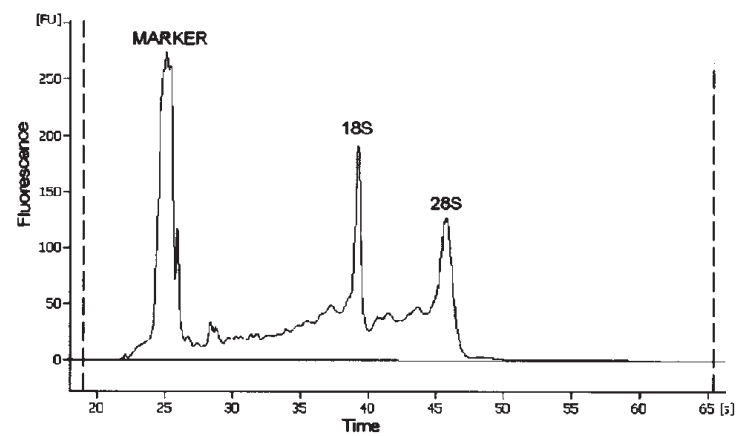

Figure 4. Integrity of RNA isolated from plasma samples, MNC or MCF7 cells. The integrity of RNA samples isolated from the plasma of a healthy volunteer, breast cancer patient, MNC from a healthy volunteer and MCF7 cells was analyzed using capillary electrophoresis. The right electropherograms show total RNA isolated from MNC (above) or MCF7 (below). RNA of acceptable quality exhibits the 18S and 28S subunit as two distinct bands. The left electropherograms show highly degraded total RNA from one representative plasma sample from a healthy volunteer (above) and a breast cancer patient (below). In these samples the typical $18 \mathrm{~S}$ and $28 \mathrm{~S}$ subunits were not detectable, but the whole RNA was grouped around the marker band. 
A. RNA INTEGRITY IN FRESH PLASMA

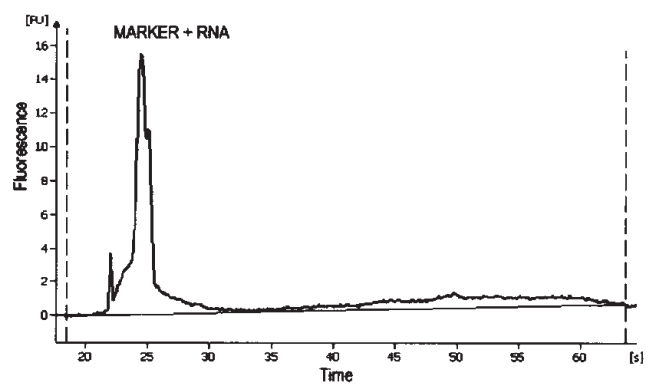

B. RNA INTEGRITY IN ONCE-FROZEN PLASMA WITHOUT TRIZOI LS

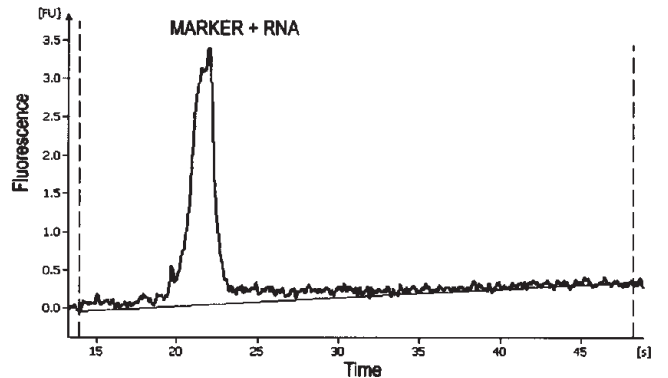

C. RNA INTEGRITY IN ONCE-FROZEN PLASMA WITH TRIZOI LS

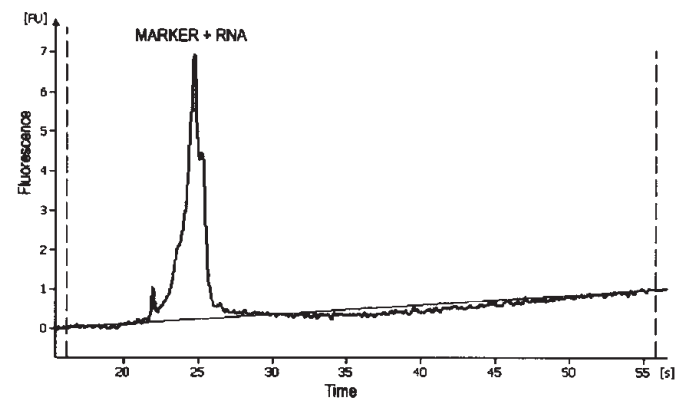

D. RNA INTEGRITY

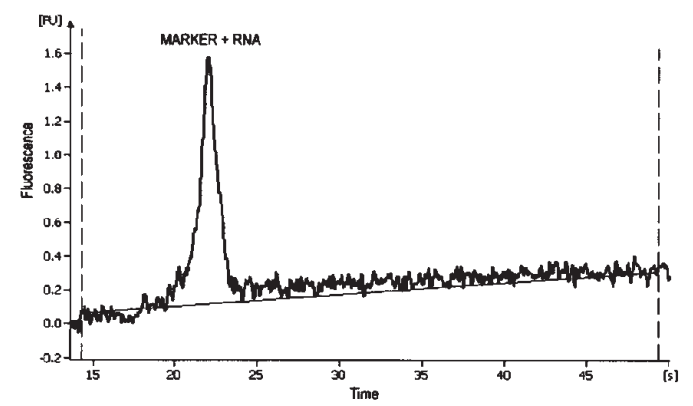

PBGD TRANSCRIPTS

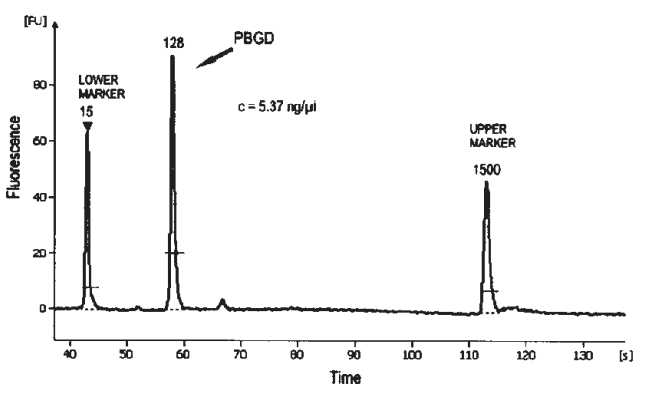

PBGD TRANSCRIPTS
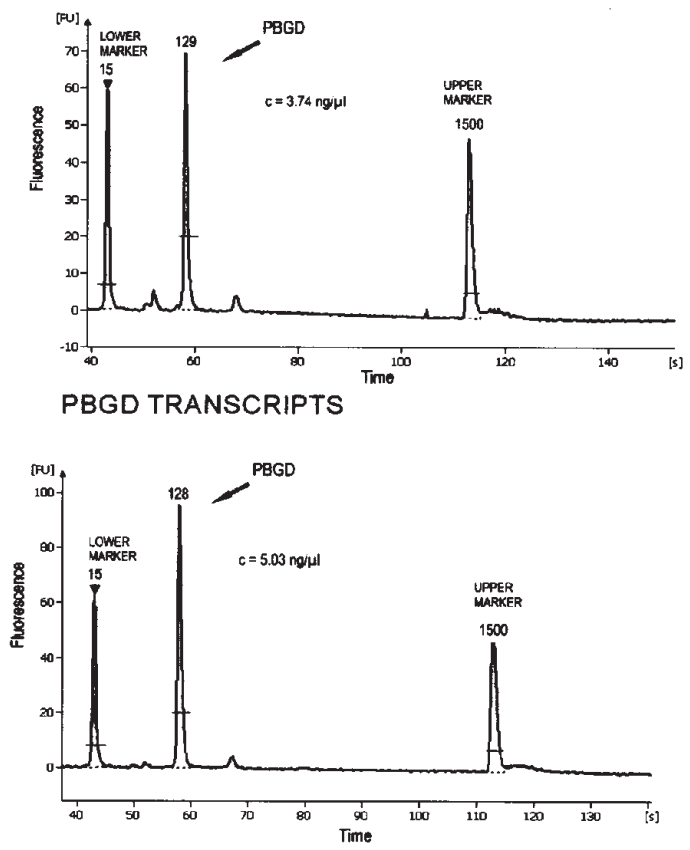

FAILED PBGD AMPLIFICATION

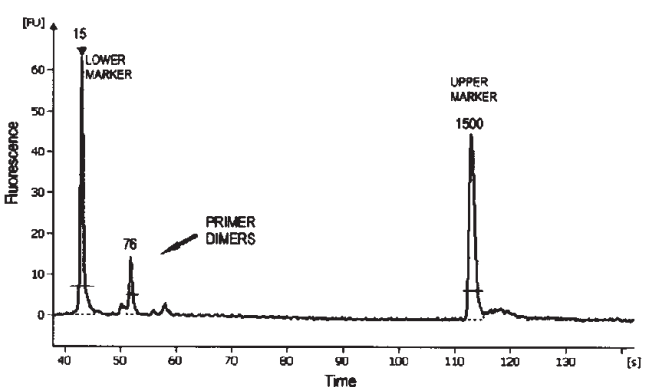

Figure 5. Example of integrity of RNA obtained from fresh and once-frozen plasma. Determination of RNA integrity by capillary electrophoresis and determination of the RT-PCR-amplified PBGD in a plasma sample obtained from the same healthy volunteer. Right electropherograms show PBGD transcripts after RT-PCR in differently pre-treated plasma aliquots. The amplification of PBGD was not possible (in 1 sample) on account of overly degraded RNA (D).

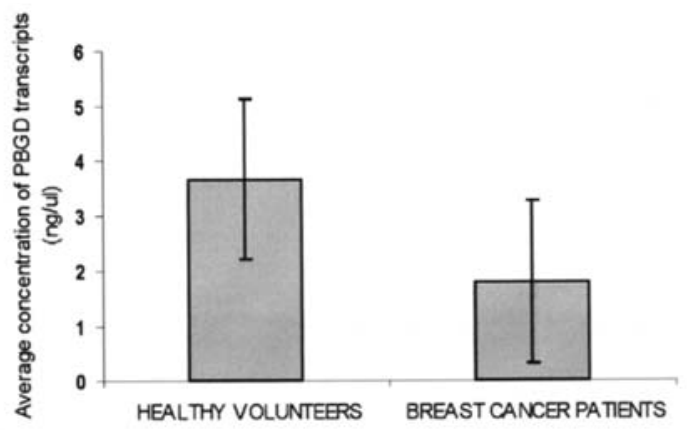

Figure 6. Average concentration (mean \pm SD) of PBGD RT-PCR products amplified from total RNA isolated from plasma samples of healthy volunteers and breast cancer patients. The significant difference of PBGD concentrations between healthy volunteers and breast cancer patients was determined $(\mathrm{P}<0.001)$. PBGD was amplified from RNA isolated from concentrated and once-frozen plasma samples (24 from healthy volunteers and 67 from breast cancer patients). The concentrations of the PCRamplified product were determined using capillary electrophoresis. 


\section{Discussion}

Accurate and early detection of cancer, as well as of its differential diagnosis, is a prerequisite for successful treatment. Since cancer cells are genetically unstable, it is reasonable to anticipate that techniques of molecular biology will provide some useful information about cancer development at an early stage of carcinogenesis. Unfortunately, the collection of samples for molecular diagnostics is quite often connected to invasive procedures, thus limiting the wider application of these methods. In the last few years, considerable interest has been focused on the evaluation of circulating nucleic acids in the plasma/serum of cancer patients.

Various studies report the use of plasma/serum DNA and RNA for prognostication and diagnosis of different types of malignancies (13-20). Circulating DNA exhibits tumor-related alterations, such as decreased strand stability (21), Ras or $p 53$ mutations, microsatellite alterations and aberrant promoter hypermethylation of tumor suppressor genes, rearranged immunoglobulin heavy-chain DNA, mitochondrial DNA mutations and tumor-related viral DNA (22).

Unexpectedly, circulating plasma/serum RNA was also found to be detectable in patients with breast cancer, colon cancer, lung cancer and malignant melanoma (1-9). The advantage of plasma/serum RNA-based assays over plasma/ serum DNA-based assays is that the RNA in plasma/serum has been shown to be tumor and tissue-type specific, thus potentially indicating the presence of a tumor as well as the tissue where the tumor cells emerge $(19,20)$. RNA-based assays are, on the other hand, limited by the tedious and demanding isolation methods required, and by the lesser stability of RNA compared to DNA.

The special interest of this study was to improve the procedure of RNA isolation from a large volume of plasma. In this manner, prior to RNA isolation using TRIzol LS, the step of plasma concentrating was introduced. Because of the potential influence of this additional step, RNA quality and quantity were investigated. Concomitantly, the effect of freezing/thawing of plasma samples on RNA quality and quantity was evaluated. The question of whether plasma RNA is still amplifiable after the freezing/thawing of plasma samples is highly important for at least two reasons: handling of plasma/serum samples obtained at different times and in different hospitals, and because of the application of prebanked samples stored at $-80^{\circ} \mathrm{C}$. We have demonstrated that the freezing/thawing of plasma did not significantly change RNA concentrations and integrity in comparison with fresh plasma. There was also no difference in the frozen samples with or without TRIzol LS. This finding is in agreement with the results reported by others who showed that the concentration and integrity of circulating RNA remain unaffected by freezing and thawing $(10,12)$. These data also indicated that plasma RNA is not as labile as previously assumed and that it is protected against ribonuclease activity. According to various authors, it seems that the major protection of RNA in plasma derives from its inclusion within apoptotic bodies. One line of empirical evidence corroborating this statement was provided by $\mathrm{Ng}$ et al, who demonstrated the presence of filterable and non-filterable RNA species in plasma after filtration of plasma samples through filters with different pore sizes (11). Also related were the findings of Tsui et al, who verified that endogenous RNA in plasma is more stable than exogenous RNA (12). In favor of the idea that RNA is protected in lipid-containing vesicles such as apoptotic bodies are El-Hefnawy et al, whose results showed that plasma RNA is more degraded after the addition of detergents SDS or Triton-X (10).

In most of the studies, plasma RNA was isolated from small amounts of plasma (50-500 $\mu 1)$, mainly because of the difficulties of scaling-up the method of RNA isolation from larger volumes $(2,4,5)$. However, small amounts of plasma could contribute to poor sensitivity of the entire method for cancer detection. To improve RNA isolation from larger volumes of plasma, El-Hefnawy et al concentrated the RNA by capturing it on $0.22-\mu \mathrm{m}$ filters (10). In our study, we introduced the step into the protocol for isolation of RNA by concentrating the plasma by evaporation at $4^{\circ} \mathrm{C}$ in a concentrator. In this way, we eliminated water from the samples, thus reducing the initial sample volume before RNA precipitation. We presumed that concentration of a larger plasma volume by this method could increase the yield of isolated RNA and reduce the costs of isolation. Indeed, our results showed that the integrity of RNA and the amount of RNA transcripts were not affected by concentrating the plasma in comparison with unconcentrated plasma samples. Using this procedure, we were able to isolate and amplify RNA from $95.80 \%$ of healthy volunteers, irrespective of the pretreatment procedure of the plasma samples (fresh or frozen samples). To confirm the results, we amplified two different housekeeping genes, PBGD and GAPDH, differing in the length of the amplified fragments (PBGD transcripts are $127 \mathrm{bp}$ long, while GAPDH transcripts are 309 bp long). In both cases the amplification of isolated RNA from concentrated and unconcentrated plasma aliquots was successful, and the RNA concentrations did not differ. An even higher percentage of samples allowing RNA isolation and amplification was reported by El-Hefnawy et al (100\%), while most other authors reported $\sim 60 \%$ of samples with detectable levels of different plasma RNAs such as B-actin mRNA, 18S rRNA and GAPDH mRNA $(10,11,23)$. Therefore, our results are completely in agreement with the results of El-Hefnawy et al supporting the idea of plasma concentration prior to RNA isolation, thus facilitating isolation from larger volumes of plasma. Additionally, our results with capillary electrophoresis showed that endogenous plasma RNA is highly fragmented when compared to the RNA isolated from MCF7 or MNC, which is again in accordance with the previous report (10).

Since our ultimate goal was determining an accurate procedure for molecular diagnostics in oncology, we also tested our improved isolation protocol in plasma samples from breast cancer patients. Some previous reports indicated that cancer patients might have significantly higher plasma/serum RNA concentrations than healthy controls $(11,20)$. With regard to these studies and to the possibility that apoptosis of neoplastic cells in cancer patients might release apoptotic bodies loaded with RNA, we expected the plasma/serum RNA concentrations in breast cancer patients to be higher in comparison with healthy volunteers. However, our results were the opposite; the RNA concentrations were 
lower in breast cancer patients. Additionally, the percentage of samples with detectable levels of RNA transcripts among breast cancer patients was also lower as compared to healthy controls. As shown in one of the previous studies, this outcome could be related to the increased concentration of blood RNases in the plasma/serum of cancer patients (24). In view of the fact that we evaluated RNA quality and quantity indirectly, by quantifying the amounts of PBGD transcripts after RT-PCR, it is also quite possible that the RNA isolated from breast cancer patients amplified to a lesser extent because of its lower quality. This, however, cannot be confirmed with the methods used in our study, since the plasma RNA was highly degraded in both breast cancer patients and healthy volunteers.

Our data indicate that concentrating the initial plasma volume by evaporation did not affect RNA quality and quantity, yet it substantially reduced the volume of TRIzol LS needed for RNA isolation. At the same time, the small amount of plasma RNA pellet can be more effortlessly collected from the reduced volume of sample. In spite of the fact that the RNA isolated from plasma is heavily degraded, the amplification of at least 310-bp-long products is still allowed. In general, the described modified isolation procedure for plasma RNA using TRIzol LS has certain advantages when compared to the unmodified procedure. In view of the fragility of plasma RNA, one must first take into account the length of the gene product of each specific gene prior to considering (if this is rational at all) the optimization of its RNA isolation procedure.

\section{Acknowledgements}

This research was supported by the Slovenian Ministry of Science (grant nos. J3-6363 and J3-7488).

\section{References}

1. Lo KW, Lo YM, Leung SF, Tsang YS, Chan LY, Johnson PJ, Hjelm NM, Lee JC and Huang DP: Analysis of cell-free Epstein-Barr virus-associated RNA in the plasma of patients with nasopharyngeal carcinoma. Clin Chem 45: 1292-1294, 1999.

2. Kopreski MS, Benko FA, Kwak LW and Gocke CD: Detection of tumor messenger RNA in the serum of patients with malignant melanoma. Clin Cancer Res 5: 1961-1965, 1999.

3. Novakovic S, Hocevar M, Zgajnar J, Besic N and Stegel V: Detection of telomerase RNA in the plasma of patients with breast cancer, malignant melanoma or thyroid cancer. Oncol Rep 11: 245-252, 2004.

4. Chen XQ, Bonnefoi H, Pelte MF, Lyautey J, Lederrey C, Movarekhi S, Schaeffer P, Mulcahy HE, Meyer P, Stroun M and Anker P: Telomerase RNA as a detection marker in the serum of breast cancer patients. Clin Cancer Res 6: 3823-3826, 2000.

5. Dasi F, Lledo S, Garcia-Granero E, Ripoll R, Marugan M, Tormo M, Garcia-Conde J and Alino SF: Real-time quantification in plasma of human telomerase reverse transcriptase (hTERT) mRNA: a simple blood test to monitor disease in cancer patients. Lab Invest 81: 767-769, 2001
6. Miura N, Shiota G, Nakagawa T, Maeda Y, Sano A, Marumoto A, Kishimoto Y, Murawaki Y and Hasegawa J: Sensitive detection of human telomerase reverse transcriptase mRNA in the serum of patients with hepatocellular carcinoma. Oncology 64: 430-434, 2003.

7. Hasselmann DO, Rappl G, Rossler M, Ugurel S, Tilgen W and Reinhold U: Detection of tumor-associated circulating mRNA in serum, plasma and blood cells from patients with disseminated malignant melanoma. Oncol Rep 8: 115-118, 2001.

8. Silva JM, Dominguez G, Silva J, Garcia JM, Sanchez A, Rodriguez O, Provencio M, Espana P and Bonilla F: Detection of epithelial messenger RNA in the plasma of breast cancer patients is associated with poor prognosis tumor characteristics. Clin Cancer Res 7: 2821-2825, 2001.

9. Wong SC, Lo SF, Cheung MT, Ng EK, Tse CW, Lai BS, Lee KC and Lo YM: Quantification of plasma beta-catenin mRNA in colorectal cancer and adenoma patients. Clin Cancer Res 10: 1613-1617, 2004

10. El-Hefnawy T, Raja S, Kelly L, Bigbee WL, Kirkwood JM, Luketich JD and Godfrey TE: Characterization of amplifiable, circulating RNA in plasma and its potential as a tool for cancer diagnostics. Clin Chem 50: 564-573, 2004.

11. Ng EK, Tsui NB, Lam NY, Chiu RW, Yu SC, Wong SC, Lo ES, Rainer TH, Johnson PJ and Lo YM: Presence of filterable and nonfilterable mRNA in the plasma of cancer patients and healthy individuals. Clin Chem 48: 1212-1217, 2002.

12. Tsui NB, Ng EK and Lo YM: Stability of endogenous and added RNA in blood specimens, serum, and plasma. Clin Chem 48: 1647-1653, 2002

13. Chen XQ, Stroun M, Magnenat JL, Nicod LP, Kurt AM, Lyautey J, Lederrey $\mathrm{C}$ and Anker P: Microsatellite alterations in plasma DNA of small cell lung cancer patients. Nat Med 2: 1033-1035, 1996.

14. Hibi K, Robinson CR, Booker S, Wu L, Hamilton SR, Sidransky D and Jen J: Molecular detection of genetic alterations in the serum of colorectal cancer patients. Cancer Res 58: 1405-1407, 1998.

15. Taback B, Fujiwara Y, Wang HJ, Foshag LJ, Morton DL and Hoon DS: Prognostic significance of circulating microsatellite markers in the plasma of melanoma patients. Cancer Res 61: 5723-5726, 2001

16. Hickey KP, Boyle DP, Jepps HM, Andrew AC, Buxton EJ and Burns PA: Molecular detection of tumor DNA in serum and peritoneal fluid from ovarian cancer patients. Br J Cancer 80: 1803-1808, 1999.

17. Taback B, Giuliano AE, Hansen NM and Hoon DS Microsatellite alterations detected in the serum of early stage breast cancer patients. Ann NY Acad Sci 945: 22-30, 2001.

18. Rogers A, Joe Y, Manshouri T, Dey A, Jilani I, Giles F, Estey E, Freireich E, Keating M, Kantarjian H and Albitar M: Relative increase in leukemia-specific DNA in peripheral blood plasma from patients with acute myeloid leukemia and myelodysplasia. Blood 103: 2799-2801, 2004.

19. Tong YK and Lo YMD: Diagnostic developments involving cell-free (circulating) nucleic acids. Clin Chim Acta 363: 187-196, 2006.

20. Goebel G, Zitt M and Muller HM: Circulating nucleic acids in plasma or serum (CNAPS) as prognostic and predictive markers in patients with solid neoplasias. Dis Markers 21: 105-120, 2005.

21. Stroun M, Anker P, Maurice P, Lyautey J, Lederrey C and Beljanski M: Neoplastic characteristics of the DNA found in the plasma of cancer patients. Oncology 46: 318-322, 1989.

22. Anker P, Mulcahy H, Chen XQ and Stroun M: Detection of circulating tumor DNA in the blood (plasma/serum) of cancer patients. Cancer Metastasis Rev 18: 65-73, 1999.

23. Pelosi G, Schianchi E, Dell'Orto P, Veronesi G, Spaggiari L, Pasini F, Sozzi G, Brambilla E, Griso C and Viale G: Detecting cell-free circulating hTERT mRNA in the plasma may identify a subset of nonsmall cell lung cancer patients. Virchows Arch 448: 7-15, 2006.

24. Reddi KK and Holland JF: Elevated serum ribonuclease in patients with pancreatic cancer. Proc Natl Acad Sci USA 73: 2308-2310, 1976. 